\title{
PROPOSTA DE IMPLANTAÇÃO DO PLANO DE GERENCIAMENTO DE RESÍDUOS SÓLIDOS EM INSTITUIÇÃO DE ENSINO SUPERIOR
}

\author{
Carolline Barbosa da Silva ${ }^{1}$ \\ Igor Pirino Bernardo Rodrigues ${ }^{2}$ \\ Sergio Luiz Damiati ${ }^{3}$
}

Resumo: A correta gestão dos resíduos sólidos, assunto muito discutido devido ao crescimento desenfreado da população e seu modo de vida, representa um dos maiores desafios que a sociedade moderna tem enfrentado. O presente artigo tem como objetivo discutir a implementação de um Plano de Gerenciamento de Resíduos Sólidos (PGRS) em uma instituição de Ensino Superior. A metodologia adotada foi um estudo de caso, identificando os resíduos gerados, forma de armazenamento e destinação, benefícios econômicos, sociais e ambientais, sugestões de aperfeiçoamento para um efetivo gerenciamento, conforme previsto na Lei 12.305/2010 que institui a Política Nacional de Resíduos Sólidos. Palavras-chave: Responsabilidade ambiental; Coleta seletiva; Resíduos sólidos; Lei 12.305/2010; Política Nacional de Resíduos Sólidos.

\footnotetext{
1 Engenharia Ambiental e Sanitária, Faculdades Metropolitana Unidas, Brasil. E-mail: carolline.b.silva@hotmail.com.

2 Engenharia Ambiental e Sanitária, Faculdades Metropolitana Unidas, Brasil. E-mail: igorpirino@hotmail.com. 3 Engenharia Ambiental e Sanitária, Faculdades Metropolitana Unidas, Brasil. E-mail: sergio.damiati@fmu.br.
} 